\title{
LOS CONTRATOS DE CONSUMO EN EL DERECHO INTERNACIONAL PRIVADO DE FUENTE INTERNA. LA REGULACIÓN DEL CÓDIGO CIVIL Y COMERCIAL DE LA NACIÓN
}

\author{
Germán E. Gerbaudo
}

Profesor Titular Ordinario por Concurso de Derecho de la Insolvencia, Facultad de Derecho,

Universidad Nacional de Rosario.

\section{Resumen}

En este trabajo se analiza el régimen de Derecho Internacional Privado de fuente interna de los contratos de consumo previsto en el Código Civil y Comercial de la Nación. Se estudia las normas que establecen las pautas de jurisdicción y de derecho aplicable. Asimismo, se observa la ausencia de un régimen especial para regular los contratos de consumo internacionales celebrados a través del comercio electrónico. 


\section{Introducción}

En la actualidad vivimos en un mundo signado por la globalización, que provoca una constante apertura de los mercados a productos y servicios extranjeros. Ello determina que los contratos internacionales de consumo se presenten cada vez con mayor frecuencia, movilizando de manera constante bienes y dinero por encima de las fronteras de los Estados. En tal sentido, acertadamente se afirma que "el derecho del consumidor tiene una vocación internacional" (Vid. ELLERMAN, Ilse, La jurisdicción internacional en el ámbito del derecho del consumo: alternativas y propuestas, en "Los derechos del consumidor. Visión internacional. Una mirada interna", DREYZIN DE KLOR, Adriana (Directora)-ELLERMAN, Ilse (Coord.), Buenos Aires, Zavalía, 2012, p. 33).

En ese escenario se intensifica la situación de vulnerabilidad en que se encuentran los consumidores. Es por ello que las relaciones de consumo internacional "presentan especificidades que han llevado a la reformulación de las reglas y los principios que rigen el el DIPr. clásico" (Vid. ELLERMAN, I., op. cit., p. 33)

En este trabajo analizamos el régimen internacional de los contratos de consumo en la regulación dada por el Código Civil y Comercial de la Nación. Concretamente estudiaremos el régimen contenido en el Título IV "Disposiciones de Derecho Internacional Privado", Capítulo 3 "Parte especial", Sección 12 " "Contrato de consumo" que aloja a los arts. 2654 y 2655 . El primero se ocupa de la jurisdicción y el segundo del derecho aplicable ${ }^{1}$.

Con esta regulación el Código Civil y Comercial de la Nación viene a resolver una laguna que se presentaba ante el crecimiento frecuente de los contratos de consumo de carácter internacio- nal. Es preciso señalar que "la ley 24.240 (t.o. ley 26.994) no contemplaba directivas para esta categoría en particular, aunque la realidad jurídica denotaba la permanente verificación de esta figura en la práctica y la necesidad de la jurisprudencia de expedirse sobre el particular" (Vid. SAUCEDO, Ricardo J., Los contratos internacionales en el Código Civil y Comercial de la Nación, en Suplemento Jurisprudencia Argentina 20/03/2019, p. 3, Jurisprudencia Argentina 2019-I).

Asimismo, cabe señalar que el contrato internacional de consumo es el único contrato en particular que el legislador optó por regular entre las normas de Derecho Internacional Privado -Código Civil y Comercial- , haciéndolo en materia de jurisdicción y derecho aplicable (Vid. UZAL, María Elsa, Los contratos internacionales en el DIPr. Argentino a la luz del Código Civil y Comercial de la Nación, en "Revista del Código Civil y Comercial", 2017 (septiembre), p. 137; IUD, Carolina D., Introducción a la regulación de los contratos internacionales de consumo en el Código Civil y Comercial de la Nación, en "Revista del Código Civil y Comercial” 2017 (septiembre), p. 158; IUD, Carolina D., La jurisdicción internacional en contratos electrónicos concluidos por consumidores, en La Ley 2018-A, p. 227; ROSA VILARDO, María Laura, Los jueces internacionalmente competentes en un caso de consumidores internacionales, en Suplemento Jurisprudencia Argentina 21/02/2018, p. 26; Jurisprudencia Argentina 2018-I, p. 85 y en "Revista de Derecho Comercial y de las Obligaciones" No 290, p. 643; IÑíGUEZ, Marcelo D., Breve historia del Derecho internacional Privado en la Argentina, en Suplemento Jurisprudencia Argentina 7/11/2018, p, 135, Jurisprudencia Argentina 2018 -IV; MENICOCCI, Alejandro A., Jurisdicción internacional directa en materia de contratos en el Código Civil y Comercial de la Nación, en El

1El Código Civil y Comercial fue sancionado por la ley 26.994 el 8 de octubre de 2014 y se encuentra vigente desde el 1 de agosto de 2015. 
Derecho 3/09/2018, p. 1$)^{2}$.

Además, en una mirada más amplia del Derecho Internacional Privado es menester señalar que el Código Civil y Comercial significó un gran avance en la materia al regular de manera agrupada diversos institutos de la materia. La regulación del Código Civil y Comercial es recibida con beneplácito por parte de la doctrina que señala que con ello "se ha renovado el derecho internacional privado de fuente interna" (Vid. RIVERA, Julio César, El Código Civil y Comercial a cuatro años de vigencia. A propósito del Anteproyecto de reformas, Suplemento Jurisprudencia Argentina 10/07/2019, p. 5, Jurisprudencia Argentina 2019-III).

\section{Calificaciones.}

Uno de los grandes problemas que se suscitan en el Derecho Internacional Privado es el de las calificaciones. Este problema se presenta ante la aplicación simultánea de más de un ordenamiento normativo que pueden utilizar un mismo término con diferente significado.

En la regulación de Derecho Internacional Privado de fuente interna no encontramos calificaciones de consumidor, proveedor, relación de consumo y contrato de consumo. De esa manera, la calificación de los mismos queda librada a la regulación doméstica del consumidor.

El tema de las calificaciones reviste importancia dado que al regular la jurisdicción internacional alude a relaciones de consumo y cuando se regla el derecho aplicable se refiere a contrato de consumo ${ }^{3}$.

En tal sentido, como hemos señalado ante la falta de calificaciones propias en la regulación internacional de los contratos de consumo debemos recurrir a las calificaciones del derecho domestico. Así, encontramos una conceptualización de las relaciones de consumo en el art. 1092, primera parte, del Código Civil y Comercial que expresa que "Relación de consumo es el vínculo jurídico entre un proveedor y un consumidor". La noción de relación de consumo se presenta como más amplia que la de contrato de consumo (Vid. FERNÁNDEZ ARROYO, Diego, comentario al art. 2654 del Código Civil y Comercial en "Código Civil y Comercial de la Nación comentado", Rivera, Julio César-Medina, Graciela (Directores) y Esper, Mariano (Coord), $1^{\mathrm{a}}$ ed., Buenos Aires, Thomson Reuters-La Ley, t. VI, 2014, p. 955).

En cuanto al consumidor el mismo precepto dice que "Se considera consumidor a la persona humana o jurídica que adquiere o utiliza, en forma gratuita u onerosa, bienes o servicios como destinatario final, en beneficio propio o de su grupo familiar o social". Seguidamente establece que "Queda equiparado al consumidor quien, sin ser parte de una relación de consumo como consecuencia o en ocasión de ella, adquiere o utiliza bienes o servicios, en forma gratuita u onerosa, como destinatario final, en beneficio propio o de su grupo familiar o social".

La calificación doméstica de contrato de consumo se encuentra en el art. 1093 que dispone que "Contrato de consumo es el celebrado entre un consumidor o usuario final con una persona humana o jurídica que actúe profesional u ocasionalmente o con una empresa productora de bienes o prestadora de servicios, pública o privada, que tenga por objeto la adquisición, uso o goce

\footnotetext{
${ }^{2}$ Desde otro punto de vista también se observa una diferencia con la regulación doméstica en materia de contratos que regulan los contratos paritarios, de adhesión y de consumo. En el ámbito de la regulación de Derecho Internacional Privado solo se regulan los contratos paritarios y los de consumo (Véase: IÑíGUEZ, Marcelo D., Disposiciones de Derecho Internacional Privado. Parte Especial, en Suplemento Jurisprudencia Argentina 18/11/2015, p. 40; Jurisprudencia Argentina 2015-IV, p. 804 ${ }^{3} \mathrm{El}$ art. 2664 del Código Civil y Comercial reza "Las demandas que versen sobre relaciones de consumo...." En tanto que el art. 2665 dispone que "Los contratos de consumo se rigen..."
} 
de los bienes o servicios por parte de los consumidores o usuarios, para su uso privado, familiar o social".

\section{Jurisdicción.}

La jurisdicción internacional refiere a "la distribución de competencias entre Estados en casos jusprivatistas internacionales" (Vid. SOTO, Alfredo M., Temas estructurales del derecho internacional privado, $1^{\text {a }}$ ed., Estudio, Buenos Aires, 2009, p. 59).

El art. 2654 se ocupa de determinar quién es el juez aplicable estableciendo diversas pautas jurisdiccionales.

El citado precepto bajo la designación de "jurisdicción" dispone que "Las demandas que versen sobre relaciones de consumo pueden interponerse, a elección del consumidor, ante los jueces del lugar de celebración del contrato, del cumplimiento de la prestación del servicio, de la entrega de bienes, del cumplimiento de la obligación de garantía, del domicilio del demandado o del lugar donde el consumidor realiza actos necesarios para la celebración del contrato.

También son competentes los jueces del Estado donde el demandado tiene sucursal, agencia o cualquier forma de representación comercial, cuando éstas hayan intervenido en la celebración del contrato o cuando el demandado las haya mencionado a los efectos del cumplimiento de una garantía contractual.

La acción entablada contra el consumidor por la otra parte contratante sólo puede interponerse ante los jueces del Estado del domicilio del consumidor.

En esta materia no se admite el acuerdo de elección de foro".
La norma que analizamos contempla tres supuestos diferentes: 1) consumidor actor; 2) consumidor demandado; 3) No se admite el acuerdo de elección de foro -sea el consumidor actor o demandado-

\section{1) Consumidor actor.}

El art. 2654 establece diversas pautas jurisdiccionales que funcionan de manera alternativa y que toman en consideración "la situación del consumidor llamado pasivo, esto es, aquel a quien se lo ha buscado, por así decirlo, para consumir" (Vid. SOTO, Alfredo Mario, comentario al art. 2654 del Código Civil y Comercial, en "Código Civil y Comercial comentado. Tratado exegético", Alterini, Jorge H. (Director General), $1^{\circ}$ ed., Buenos Aires, t. XI, 2015, E-book).

Se considera al consumidor como la parte débil de esa relación y con ello se establecen diversos foros alternativos a elección del consumidor, a saber:

- del lugar de celebración del contrato;

- del cumplimiento de la prestación del servicio;

— de la entrega de bienes;

— del cumplimiento de la obligación de garantía;

— del lugar donde el consumidor realiza actos necesarios para la celebración del contrato;

— del domicilio del demandado ${ }^{4}$.

- Son también competentes los jueces del Estado donde el demandado tiene sucursal, agencia o cualquier otra forma de representación comercial, cuando hayan intervenido en la celebración del contrato o cuando el demandado las haya mencionado a los efectos del cumplimiento de una garantía contractual.

\footnotetext{
${ }^{4}$ No se incluye el lugar de residencia habitual del demandado como sí se establece en el inc. 1) del art. 2650 del Código Civil y Comercial cuando establece las pautas atributivas de jurisdicción para los contratos en general.
} 
Se observa que se establecen "siete foros abiertos al consumidor" (Vid. TONIOLLO, Javier A., Los contratos de consumo y la responsabilidad por el producto en el Derecho Internacional Privado Argentino. Análisis desde y para una perspectiva global, en Suplemento Jurisprudencia Argentina 18/05/2016, p. 90). Se indica que hay "un abanico de foros disponibles, todos ellos razonablemente previsibles, a favor del consumidor actor y para garantizar y facilitar su acceso a la justicia" (Vid. UZAL, María Elsa, Lineamientos de la reforma del Derecho Internacional Privado en el Código Civil y Comercial de la Nación, en Suplemento Especial "Nuevo Código Civil y Comercial", 2014 (noviembre), p. 247). En similar sentido se expresa que "suministra al consumidor actor, un abanico de foros concurrentes ante los cuales impetrar sus reclamos por un contrato de esta naturaleza" (Vid. SAUCEDO, Ricardo J., Los contratos internacionales en el Código Civil y Comercial de la Nación, en Suplemento Jurisprudencia Argentina 20/03/2019, p. 3, Jurisprudencia Argentina 2019-1). Asimismo, se expresa que "prevé un abanico de foros disponibles, razonablemente previsibles" (Vid. PORCELLI, Adriana, Regulación jurídica de los contratos internacionales en el Código Civil y Comercial de la Nación, en "Revista Electrónica del Instituto de Investigaciones Ambrosio L. Gioja", Buenos Aires, Facultad de Derecho, Universidad Nacional de Buenos Aires, año IX, No 15, 2015, p. 79.). También se expresa que la norma "instaura varias conexiones procesales cuando la parte débil actúa como demandante" (Vid. URIONDO DE MARTINOLI, Amalia, EI consumidor internacional, en Suplemento Jurisprudencia Argentina 20/09/2017, p. 128; Jurisprudencia Argentina 2017-III, p. 1453).

Se trata de una norma abierta que permite el más amplio acceso a la jurisdicción al consumidor. Hay una amplitud de acceso a la jurisdicción a favor del consumidor que es la parte débil del contrato. Se establecen opciones alternativas en cabeza del consumidor en forma amplia.

No obstante, es preciso indicar que la norma que analizamos no ha establecido como foro a favor del consumidor el del juez de su domicilio. Esta solución es criticada por Sara Feldstein de Cárdenas quien expresa que "en lo que se relaciona específicamente con la cuestión de la jurisdicción internacional no deja de sorprendernos, y esta es una omisión desafortunada, la falta de previsión legislativa del foro de protección del consumidor, que le permitiría iniciar su acción ante los tribunales del lugar de su propio domicilio. Esta decisión legislativa, según creemos, se encuentra a contramano, en total desacuerdo con las tendencias actuales en la legislación comparada tanto de fuente interna como convencional" (Vid. FELDSTEIN DE CARDENAS, Sara L., Desprotección del consumidor transfronterizo. Hitos en el derecho Latinoamericano contemporáneo, en La Ley 2015-B, p. 727). Igualmente, se expresa que se lo está "despojándolo del foro más accesible para la defensa y la protección acabada de sus derechos" (Vid. BIELLI, Gastón E. y ORDÓÑEZ, Carlos J., Los consumidores y la contratación electrónica en el entramado normativo argentino, en La Ley 10/09/2019, p. 1).

Asimismo se ha dicho que si bien la omisión de la pauta del domicilio del demandado es grave, a poco que se analice la amplia gama de casos en los cuales el art. 2654 del Código Civil y Comercial permite al consumidor domiciliado en la República Argentina acudir ante los tribunales locales, se advierte que en la realidad concreta serían muy pocos los casos en los que el consumidor domiciliado en la Argentina no pudiera acudir a los tribunales locales. Agregando que en esos casos se puede acudir a la aplicación del foro de necesidad del art. 2602 del Código Civil y Comercial (Vid. IUD, Carolina D., Introducción..., cit., p. 158). 


\section{2) Consumidor demandado.}

En caso que el demandado sea el consumidor la acción solo puede entablarse ante los jueces del Estado del domicilio del consumidor demandado. La norma se cierra. En otros términos, se indica que "el profesional no tiene ninguna elección posible, desde que sólo puede demandar al consumidor ante los tribunales del Estado del domicilio del consumidor" (Vid. RIVERA, Julio César, CROVI, Luis D. y DI CHIAZZA, Iván, Contratos. Parte General, Buenos Aires, 2017, p. 583).

Es una norma protectoria del consumidor dirigida a evitar que el consumidor se vea obligado a desplazarse al exterior, o bien que se vea obligado a defenderse en un Estado diferente (Vid. IUD, Carolina D., La jurisdicción internacional en contratos electrónicos concluidos por consumidores, en L.a ley 2018-A, p. 227).

\section{3) Prohibición de elección de foro.}

En el último párrafo se veda el ejercicio de la autonomía de la voluntad. Es decir, se dispone la imposibilidad de la celebración del acuerdo de selección de foro. Claramente aquí se tiene en consideración que el consumidor es la parte débil de esa relación y se procura evitar el aprovechamiento del proveedor. En tal sentido se expresa que "esto importa la ineficacia del cualquier cláusula -impuesta o negociada- que establezca una jurisdicción determinada. Esta disposición es irrenunciable" (Vid. RIVERA, Julio César, CROVI, Luis D. y DI CHIAZZA, Iván, op. cit., p. 583).

La norma que analizamos concuerda con lo dispuesto por el art. 1109 del Código Civil y Comercial que reputa a la cláusula de prórroga como no escrita, catalogándola como una cláusula abu- siva (Vid. RABINO, Mariela Carina, El contrato de consumo con elementos internacionales, SAIJ, Sistema Argentino de Información Jurídica, 12 de junio de 2018, DACF180106).

No obstante, un sector de la doctrina considera que se debería haber permitido la elección del foro "siempre que se evalúe la validez del mismo considerando los límites establecidos en los principios de orden público internacional que en especial se imponen en materia de consumo" (Vid. ROSA VILARDO, M, op. cit. p. 85).

También se indica que "inexplicablemente, la norma prohíbe a ambas partes la elección del foro, cuando tratándose de una regla de protección de la parte débil, debiera haber sido facultativo el postular la nulidad solo por esta última" (Vid. MENICOCCI, A., op. cit., p. 1).

Asimismo, en las XXVI Jornadas Nacionales de Derecho Civil, llevadas a cabo en La Plata los días 28, 29 y 30 de septiembre de 2017 se concluyó de manera unánime que "De Lege Ferenda cabría examinar la posibilidad de los acuerdos de elección de foro como cláusula asimétrica favorable al consumidor, es decir, en la medida que le permita plantear su demanda ante tribunales distintos de los indicados en el art.2654 del Cód. Civ. y Com" 5 .

Cabe en este sentido señalar que en algunos antecedentes que precedieron al actual texto legal se admitía la elección del foro. Así el ejercicio de la autonomía de la voluntad en la elección del foro se preveía en el art. 945 del Proyecto de Reforma del Código Civil de 1993, en tanto el acuerdo fuera posterior al nacimiento del diferendo. De manera semejante lo admitía el art. 2563 del Proyecto de Ley de Unificación de los Códigos Civil y de Comercio de 1998. No obstante, la actual solución del art. 2654 se encuentra en línea con

${ }^{5}$ Conclusiones Comisión No 11 "Derecho Internacional Privado: "Consumidor internacional", XXVI Jornadas Nacionales de Derecho Civil, llevadas a cabo en La Plata los días 28, 29 y 30 de septiembre de 2017, en "Revista del Código Civil y Comercial" 2017 (noviembre), p. 231. 
el Proyecto de Código de Derecho Internacional Privado de 2003 (Vid. IUD, C., Introducción a la regulación..., cit., p. 158; IUD, Carolina D., La jurisdicción..., cit., p. 227).

\section{La aplicación del foro de necesidad.}

En materia de contratación electrónica nuestra jurisprudencia ha receptado el denominado foro de necesidad. El Código Civil y Comercial incorporó el foro de necesidad en el art. 2602 que expresa "Aunque las reglas del presente Código no atribuyan jurisdicción internacional a los jueces argentinos, éstos pueden intervenir, excepcionalmente, con la finalidad de evitar la denegación de justicia, siempre que no sea razonable exigir la iniciación de la demanda en el extranjero y en tanto la situación privada presente contacto suficiente con el país, se garantice el derecho de defensa en juicio y se atienda a la conveniencia de lograr una sentencia eficaz"6.

De esa manera, los jueces argentinos, siempre que se respeten los requisitos de la norma citada pueden declararse competentes (Vid. ANTÓN PÉREZ, Mariana, BALTAR, Leandro y SCOTTI, Luciana, Las fuentes del derecho internacional privado. Cuando una incorrecta fuente desencadena una serie de errores, en La Ley 2018-F, p. 467).

El foro de necesidad surge en la jurisprudencia en la causa "Vlasov"7. Se trata de una manifestación de la evitación del daño (Vid. GALDÓS, Jorge M., Responsabilidad civil preventiva. Aspectos sustanciales y procesales", en La Ley 2017-E, p. 1142). Se faculta al juez argentino que no es competente a intervenir a partir de este foro de necesidad, justificado en la situación dañosa (Vid. CORTEZ, Juan Manuel, El derecho de daños y su función preventiva en el Derecho Internacional Preventivo Argentino, en La Ley 2017-A, p.

${ }^{6}$ El Código Civil de Vélez Sarsfield de 1869 no contemplaba el foro de necesidad. La fuente del actual art. 2602 del Código Civil y Comercial está dada por los arts. 2500 del Libro VIII del Proyecto de Código Civil unificado con el Código de Comercio de 1998 y el art. 19 del Proyecto de Código de Derecho Internacional Privado Argentino del año 2003.

Se asemeja al texto del art. 19 del Proyecto de 2003 con las siguientes salvedades el cambio de la expresión "la causa" por la "situación privada" y "vínculo" por contacto (Véase: PASCUARELLI, Jorge D., Algunos aspectos de la regulación de la jurisdicción internacional en el Código Civil y Comercial de la Nación, en Suplemento Jurisprudencia Argentina 18/11/2015, p. 26, Jurisprudencia Argentina 2015-IV, p. 790).

Asimismo, se indica que "también se ha tomado como base para la redacción del presente artículo la CIDIP III sobre Competencia en la Esfera Internacional para la Eficacia Territorial de las Sentencias Extranjeras, que en su art. $2^{\circ}$ establece que se considerará satisfecho el requisito de la jurisdicción en la esfera internacional si a criterio del órgano jurisdiccional internacional del Estado parte en el que deba surtir efectos, el órgano judicial que pronunció la sentencia asumió competencia para evitar denegación de justicia por no existir órgano jurisdiccional competente" (Véase: QUARANTA COSTERG, Juan Pablo, Identificación de problemas sobre jurisdicción internacional. Soluciones, en El Derecho 10/07/2017, p. 1).

${ }^{7}$ CSJN, "E. Cavura de Vlasov c. A. Vlasov", 25/03/1960, en La Ley 98-287 y en Fallos 246:87.

Se trató de un caso de divorcio y separación de bienes. La CSJN abrió la jurisdicción argentina y consideró competentes a los tribunales argentinos dado que, si no lo hacía, se colocaba a la actora en una situación de indefensión, corriendo peligro de no encontrar un tribunal en el mundo ante el cual incoar la demanda, en virtud de que el demandado tenía domicilio nómade. La actora demandó ante los tribunales argentinos y el demandado opuso excepción de incompetencia argumentando que su domicilio estaba en Génova (Italia) y por tanto que eran competentes los jueces de tal ciudad. El juez de primera instancia rechazó la excepción, mientras que la Cámara de Apelaciones, por el contrario, declaró la incompetencia de los jueces argentinos. La CSJN consideró que los tribunales argentinos tenían jurisdicción. Lo fundamentó en la necesidad de controlar la garantía de defensa en juicio comprometida y por tanto, impedir una probable denegación internacional de justicia, inaceptable a la luz del derecho internacional. La Corte realizó en abstracto un análisis de la probable consideración del juez extranjero sobre su propia jurisdicción y el eventual resultado negativo de la jurisdicción foránea, lo cual llevaría a que la actora quedara privada internacionalmente de justicia si no se abría la jurisdicción argentina (Véase: SCOTTI, Luciana B., El acceso a la justicia en el Derecho Internacional Privado Argentino: nuevas perspectivas en el Código Civil y Comercial de la Nación, en "Red Sociales", Revista del Departamento de Ciencias Sociales, Universidad Nacional de Luján, Vol. 3, No 6, 2016, p, 22).

En este caso como indica Antonio Boggiano "la temida grave dificultad de un procedimiento en el extranjero hizo necesario abrir el foro argentino para hacer justicia a la actora. No puede decirse que la Corte aplicó en "Vlasov" la norma como era sino como ella estimó que debería ser" (Véase: BOGGIANO, Antonio, Derecho Internacional Público, Derecho Natural y Derecho Internacional Privado ¿Escisión entre lusnaturalismo y positivismo jurídico?, en La Ley 1990-B, p. 1082). 
796). Con este foro excepcional se alude claramente a la necesidad del actor de acceder a una jurisdicción donde plantear sus pretensiones (Vid. FERREYRA, María A. y DE ROSAS, Pablo E., EI Código Civil y Comercial de la Nación y el nuevo derecho internacional privado argentino de fuente interna, en Microjuris, MJ-DOC-7555-AR, 3 de febrero de 2016).

Se señala que "el foro de necesidad es un recurso del derecho internacional privado, con sustento esencialmente en el derecho de acceso a la justicia, mediante el cual los jueces locales pueden declarase competentes para entender en un asunto, de modo excepcional y sin perjuicio de que su ordenamiento jurídico carezca de normas que les atribuyan jurisdicción internacional, cuando se corra el riesgo de que quien pretenda efectivizar o restablecer sus derechos se vea enfrentado a una posible denegación de justicia" (Vid. RUBAJA, Nieve, Excesivo rigor registral: cuando la interpretación de la ley obstruye el acceso a la justicia, en "Revista de Derecho de Familia" 2019II, p. 196). También se sostiene que "el foro de necesidad es un criterio excepcional de atribución de jurisdicción, cuando la jurisdicción internacional extranjera afecta el orden público internacional argentino en sentido fuerte, es decir, por razones de justicia o equidad. Se ubica estructuralmente, así, entre las características negativas de la consecuencia jurídica de la norma indirecta referida a los problemas generales de la jurisdicción internacional" (Vid. SOTO, Alfredo M., comentario al art. 2602 del Código Civil y Comercial, en "Código Civil y Comercial comentado. Tratado exegético", Alterini, Jorge H., -Director-, $1^{\circ}$ ed., Buenos Aires, 2015, T XI, E-Book).

Para que opere el foro de necesidad y el juez argentino excepcionalmente pueda declarase competente deben concurrir una serie de requisi- tos que emergen del art. 2602 del Código Civil y Comercial, a saber:

(i) Que no sea razonable exigir la iniciación de la demanda en el extranjero;

(ii) Que la situación privada tenga contacto suficiente con el país;

(iii) Se garantice la defensa en juicio del demandado $y$,

(iv) Atienda a la conveniencia de lograr una sentencia eficaz.

Se sostiene que se establecen tantos requisitos que cuesta imaginar un caso en que logre sorteárselos a todos (Vid. SOSA, Toribio, Competencia basal en el Código Civil y Comercial. Medidas provisionales urgentes y foro de necesidad, en La Ley 2016-F, p. 619).

El foro de necesidad reviste carácter excepcional y es admitido por el legislador al efecto de evitar la denegación de justicia. Tiene por objeto garantizar un derecho fundamental como es el de acceso a la justicia, brindando una tutela judicial internacional efectiva y evitar de ese modo la denegación de justicia.

Como se advierte en este instituto "el interés de los particulares, sobre todo el de la parte actora, cobra especial relevancia en este tema tan delicado" (Vid. ALBORNOZ, María Mercedes, Acceso a la justicia en las relaciones privadas internacionales: interés en juego, en "Revista de la Secretaría del Tribunal Permanente de Revisión", Asunción, año 5, No 9, 2016, p. 170).

El foro de necesidad o forum necessitatis se conecta con el forum non conveniens ${ }^{8}$. En ambos se reconoce al juez el ejercicio de cierta discrecionalidad. Ambas especies de foros se presentan como una contracara. En el primero, esa discrecionalidad se manifiesta de manera positiva, al permitirle al juez declararse competente para asegurar la justicia; en el segundo, la discreciona-

${ }^{8}$ El forum non conveniens no se lo menciona en el Código Civil y Comercial (Véase: LÓPEZ HERRERA, Edgardo S., El derecho internacional privado en el nuevo Código, en "Revista del Código Civil y Comercial”, 2015 (julio), p. 259). 
lidad se expresa de manera negativa al permitirle al juez declinar su competencia (Vid. ALBORNOZ, op. cit., p. 170).

El peligro que conlleva el foro de necesidad es que su aplicación indiscriminada, sin atender a su carácter excepcional, puede dar lugar a la admisión indiscriminada de la jurisdicción, es decir, a un foro exorbitante (Vid. ITURBIDE, Gabriela A., El Derecho Internacional Privado y los derechos reales en el nuevo Código Civil y Comercial, en "Revista del Código Civil y Comercial" 2017 (septiembre), p. 107).

La aplicación del foro de necesidad fue admitida en materia de contratos de consumo concluidos por internet en la causa "Pérez Morales, Gonzalo Martín c/ BooKing.Com Argentina S.R.L. y otros s/ ordinario" dictado por la Sala C de la Cámara Nacional de Apelaciones en lo Comercial ${ }^{9}$.

En este caso, los hechos pueden sintetizarse señalando que el actor, que es persona humana domiciliada en la ciudad de Buenos Aires, efectuó vía el portal de Booking los días 26 y 27/02/2016 dos reservas de hoteles en Europa -en Madrid y París-. La reservas se efectivizaron por vía electrónica por la suma total de USD 1513,95, suma que abonó a través de una tarjeta de crédito Visa emitida en la República Argentina y administrada por un banco argentino, cuyo saldo era pagadero en nuestro país. Sin embargo, transcurridas menos de veinticuatro horas desde la última reserva, decide cancelar la operación vía e-mail y por comunicaciones telefónicas -al número telefónico de Argentina que figuraba en la web-, fundándose en lo establecido por el art. 14 de la ley 26.361, que sustituye el texto del art. 34 de la ley $24.240^{10}$. Por su parte, "Booking" se negó aduciendo que se trataba de una reserva bajo la modalidad "no reembolsable", que no podía reintegrarle el dinero sino que sólo podía ofrecer las fechas de las reservas, lo que recibió la negativa del consumidor.

El Sr. Pérez Morales al no obtener la restitución de la suma dineraria inició la demanda contra la representante en nuestro país. Fundó su demanda en que el actor había adquirido un producto en un sitio web ".com.ar", que muestra la bandera argentina con un número de contacto telefónico en Argentina, donde la demandada posee una sociedad con domicilio en Argentina, y la adquisición fue abonada en pesos argentinos a través de un banco argentino, mediante una compañía proveedora de internet argentina con una IP argentina. A la hora de fundar la jurisdicción de los tribunales nacionales trae en su apoyo lo dispuesto por el art. 2654 del Cód. Civil y Comercial, muy especialmente la no admisión del acuerdo de elección de foro. Además subraya que ha de considerarse a la República Argentina como lugar de celebración del contrato, que es también el lugar en el que realizó los actos necesarios para la celebración del contrato y que es también en la República Argentina donde se encuentra una representación de la demandada.

Al contestar la demanda Booking Argentina opuso la excepción de incompetencia. Basó su excepción en que Booking Argentina jamás tuvo intervención en la contratación con el accionante; indica que Booking.com B.V. (en adelante "Booking.com") es único titular y administrador del dominio "booking.com", sociedad constituida y con domicilio en Países Bajos. Por lo tanto, entiende que, en todo caso, debería acudir ante los tribunales de Ámsterdam, Holanda habida cuenta de la existencia de una cláusula de elección de foro a favor de dichos tribunales y también de derecho aplicable en favor de las leyes de dicho país. No obstante, precisa que aun cuando se considerara

${ }^{9}$ CNCom., Sala C, "Pérez Morales, Gonzalo Martín c/ BooKing.Com Argentina S.R.L. y otros s/ ordinario", 10/08/2017, en La Ley on line cita online AR/JUR/53519/2017.

${ }^{10} \mathrm{El}$ precepto regula la revocación de la aceptación. 
inválida la cláusula de elección del foro, igualmente debe tenerse en cuenta que "Booking.com BV" ha sido prestado desde una plataforma cuyos servidores están ubicados en los Países Bajos y en el Reino Unido, que la oferta fue emitida y la aceptación recibida en el exterior y que en definitiva tanto la celebración como el cumplimiento de la prestación de servicio se localizaron fuera de la República Argentina. Además, Booking Argentina agregó que la naturaleza del servicio prestado podría ser calificada como comercio electrónico directo, cuyos contactos más razonables son el lugar de celebración o el de cumplimiento. Considera que los consumos fueron en línea, teniendo en cuenta que el servicio operado fue desde una plataforma cargada en servidores ubicados en Países Bajos y Reino Unido, Booking Argentina sostiene que serían competentes los jueces de esos países, por considerarlos el lugar de celebración. También la demandada afirma la competencia de los jueces españoles y franceses en razón de ser los lugares de cumplimiento del contrato. Asimismo, Booking Argentina negó que el actor haya realizado actos de celebración del contrato desde su domicilio, como también que la sociedad haya intervenido como agencia, sucursal o representación de Booking.com, indicando que como sociedad constituida en Argentina solo se dedica al soporte comercial en el país en cuanto a las relaciones con los hoteles argentinos exclusivamente. Estima que la única forma en la que podría llegar a responsabilizarse a Booking Argentino por el accionar del Booking.com BV sería por la aplicación del art. 54 de la LGS -inoponibilidad de la persona jurídica- pero ello no fue alegado por la actora.

El juez de primera instancia, en sentencia pronunciada el 16 de febrero de 2017, desestimó la excepción de incompetencia impetrada por Booking Argentina con fundamento en el art. 2654 del Código Civil y Comercial de la Nación. La sentencia de primera instancia considera que, estando el domicilio de la demandada en la República Argentina, corresponde rechazar la excepción de incompetencia, señalando también la inadmisibilidad de los pactos de elección de foro conforme al art. 2654 del Código Civil y Comercial.

Booking Argentina apela la decisión del juez de primera instancia.

La Sala C de la Cámara Nacional de Apelaciones en lo Comercial en fecha 11 de agosto de 2017 rechaza la apelación.

La Sala comparte lo sostenido por el Fiscal en cuanto a la internacionalidad de la relación de consumo, confirmando la aplicación del art. 2654 del Cód. Civ. y Com. No obstante, el tribunal

\footnotetext{
${ }^{35}$ Sobre el tema, véase M.A. GÓMEZ SALGADO, "Robótica, empleo y Seguridad Social: la cotización de los robots para salvar el actual Estado del Bienestar», Revista Internacional y Comparada de Relaciones Laborales y Derecho del Empleo, Vol. 6, núm. 3 (2018). ${ }^{31}$ Localizable en https://www.oecd.org/spain/Employment-Outlook-Spain-ES.pdf, consultado el 6 de octubre de 2019.

${ }^{36}$ En este sentido, la ya citada Resolución del Parlamento Europeo, de 16 de febrero de 2017, con recomendaciones destinadas a la Comisión sobre normas de Derecho civil sobre robótica (2015/2103(INL)), señala que "el desarrollo de la robótica y la inteligencia artificial puede dar lugar a que los robots asuman gran parte del trabajo que ahora realizan los seres humanos sin que puedan reemplazarse por completo los empleos perdidos, cuestión esta que genera interrogantes sobre el futuro del empleo y la viabilidad de los sistemas de seguridad y bienestar sociales y sobre la insuficiencia continuada de las cotizaciones para los regímenes de jubilación, en caso de que se mantenga la actual base imponible, lo que podría acarrear una mayor desigualdad en la distribución de la riqueza y el poder, mientras que, en el marco de la financiación del apoyo y reciclaje profesional para desempleados cuyos puestos de trabajo se hayan reducido o eliminado, deberá estudiarse la posibilidad de someter a impuesto el trabajo ejecutado por robots o exigir un gravamen por el uso y mantenimiento de cada robot, a fin de mantener la cohesión social y la prosperidad».

${ }^{37}$ De fecha 22 de enero de 2019. Resumen localizable en https://www.ilo.org/wcmsp5/groups/public/---dgreports/---cabinet/ documents/publication/wcms_662541.pdf

${ }^{38}$ Pág. 4.

${ }^{39}$ Ibidem.
} 
menciona la particularidad de las operaciones por internet y destaca la dificultad de determinar la jurisdicción en un contrato celebrado en el ciberespacio, en el que las partes tienen una dirección virtual, aunque siguen teniendo actualidad los criterios atributivos reales. De esa manera, el tribunal estima que no resulta relevante la ubicación del servidor o la localización física de sus computadoras, pues el deudor podría modificar la ubicación de servidores y la conexión real dificultando ser sometido a jurisdicción alguna. Conforme a ello, al considerar un caso que resulta difícil y hasta casi imposible localizar el domicilio del demandado, la Cámara declara la competencia del juez argentino, en razón del art. 2602 que regla el foro de necesidad.

En la doctrina se ha criticado esta aplicación del foro de necesidad, por entender que se desvirtúa su carácter excepcional, más aun cuando existen normas específicas para los contratos de consumo internacionales.

Al respecto se sostiene que "entendemos perjudicial la asunción abrupta en base al foro de necesidad, porque pierde el sentido excepcional. También entendemos desalentador la utilización del foro de necesidad existiendo normas específicas de jurisdicción en materia de contratos internacionales de consumo. La sentencia de la Cámara genera un antecedente de interpretación amplia del foro de necesidad, cuando por el contrario, la misma debe ser restrictiva atento su carácter excepcional" (Vid. ROSA VILARDO, M. op. cit., p. 85).

\section{Derecho aplicable.}

El art. 2655 del Código Civil y Comercial refiere al "Derecho aplicable" disponiendo que "Los contratos de consumo se rigen por el derecho del Estado del domicilio del consumidor en los siguientes casos: a) si la conclusión del contrato fue precedida de una oferta o de una publicidad o actividad realizada en el Estado del domicilio del consumidor y éste ha cumplido en él los actos necesarios para la conclusión del contrato;

b) si el proveedor ha recibido el pedido en el Estado del domicilio del consumidor;

c) si el consumidor fue inducido por su proveedor a desplazarse a un Estado extranjero a los fines de efectuar en él su pedido;

d) si los contratos de viaje, por un precio global, comprenden prestaciones combinadas de transporte y alojamiento.

En su defecto, los contratos de consumo se rigen por el derecho del país del lugar de cumplimiento. En caso de no poder determinarse el lugar de cumplimiento, el contrato se rige por el derecho del lugar de celebración".

Claramente se observa -nuevamente- la intención de proteger a la parte débil de la relación que es el consumidor. Aquí se lo tutela mediante la aplicación del derecho de su domicilio. Se suprime también el ejercicio de la autonomía de la voluntad en la elección del derecho aplicable. En tal sentido, el precepto que analizamos cabe concordarlo con el art. 2651 que al establecer las reglas de la autonomía a de la voluntad en su parte final indica que "este artículo no se aplica a los contratos de consumo".

Comentando el art. 2655 del Código Civil y Comercial Diego Fernández Arroyo sostiene que "eso tiene sentido a poco que se piense que la situación típica tendrá como protagonista a un consumidor domiciliado en Argentina, el cual se verá ahora protegido por la propia normativa del Código. Sin embargo, no hay que descartar que en un caso concreto, otra de las leyes vinculadas con el contrato de consumo (la del domicilio del proveedor, la del lugar de la transacción, etc.) resulte más favorable para el consumidor. En tal supuesto, a pesar de lo previsto en los arts. 1094 y 
1095 que consagran el principio del favor consumitoris, la regla de DIPr. no ofrece ninguna flexibilidad. Ese contraste entre la protección reforzada del derecho material interno y la limitada del DIPr. hace resaltar aún más la evidencia de que el legislador prefirió el viejo modelo europeo al Proyecto de Convención Interamericana sobre esta materia presentado en la OEA por Argentina, Brasil y $\mathrm{Pa}$ raguay (este último basado en la aplicación de la ley más favorable al consumidor)" (Vid. FERNÁNDEZ ARROYO, D., comentario al art. 2655 del Código Civil y Comercial, cit., t. VI, p. 960)

\section{Conclusiones.}

- En la década de 1950 la relación de consumo se independiza de la clásica distinción de obligaciones contractuales y extracontractuales. La noción tradicional de contrato no daba respuesta a las exigencias de la producción en masa y la expansión de la publicidad. La oferta a personas determinadas y/o determinables fue sucedida por una oferta en masa y desperzonalizada.

Posteriormente, la globalización y el crecimiento del comercio transfronterizo generó que las relaciones de consumo se presentaran más allá de las fronteras de un Estado, en un escenario global.

- En la actualidad, el consumidor se presenta como un débil en la sociedad de consumo. Acertadamente se indica que es un ser particularmente débil, es el débil sistemático más característico de este tiempo (Vid. CIURO CALDANI, Miguel Ángel, La debilidad del consumidor en la sociedad de consumo, en "Investigación y Docencia", Rosario, Centro de Investigaciones y Filosofía Judicial, Facultad de Derecho, Universidad Nacional de Rosario, Vol 28, 1997, p. 33).

Esta debilidad se intensifica cuando se trata de contratos de consumo transfronterizos.

- En nuestro país, hasta la entrada en vigencia del Código Civil y Comercial no había normas que reglaran los contratos de consumo internacionales. Las normas previstas en la ley 24.240 de defensa del consumidor se aplican a casos puramente nacionales.

- La regulación de los contratos de consumo internacionales en el Código Civil y Comercial exhibe un claro propósito de tutela del consumidor como la parte más débil de esa relación. Esta idea-fuerza conlleva a apartarse de las reglas y principios tradicionales en materia de contratos internacionales. Se exhibe ello con nitidez al excluirse la autonomía de la voluntad tanto en materia jurisdiccional como de derecho aplicable.

El rechazo de la autonomía de la voluntad en los contratos de consumo marca una tajante diferencia con el resto de los contratos internacionales donde se la admite ampliamente.

- Una cuestión que no presenta adecuada regulación en la normativa es la referida al comercio electrónico por internet ${ }^{11}$.

Se observa en nuestro tiempo una expansión del comercio electrónico de bienes y servicios que

\footnotetext{
${ }^{11}$ En la doctrina se distingue entre el comercio tradicional, el comercio electrónico tradicional y el comercio electrónico por internet. Así se expresa que en el comercio tradicional participaban todo tipo de individuos en los negocios realizados, tanto personas físicas como personas jurídicas de derecho privado, empresas y entidades públicas. En cambio, el comercio electrónico tradicional sólo tenía lugar entre empresas y -en particular- entre entidades financieras, basándose en un sistema cerrado de participantes que se conocían mutuamente y se tenían confianza, mediante el EDI. Posteriormente, con el desarrollo de lo que se puede denominar "comercio electrónico por Internet", se expandió nuevamente el mercado, participando en él todo tipo de individuos, conocidos o desconocidos, sean personas o entidades públicas o privadas, generándose así acuerdos entre comerciantes, entre comerciantes y consumidores, entre comerciantes y la Administración pública y entre usuarios entre sí. Consecuentemente, el número de participantes limitados del comercio electrónico tradicional (sobre todo, clubes cerrados de industriales) se vuelve ilimitado mediante el comercio electrónico por Internet, dado que no existen barreras ni fronteras que puedan frenar su expansión y el mercado relevante es potencialmente infinito (Vid. HOCSMAN, Heriberto, Negocios en Internet, Buenos Aires, Astrea, 2005, ps. 7 y 8).
} 
se asienta en la utilización de redes abiertas, de fácil acceso, que potencian la internacionalización de estas operatorias, generando una disminución de costos y aumento de las ventas.

El consumidor electrónico se presenta como un consumidor hipervulnerable, existe una vulnerabilidad extrínseca relacionada a la fragilidad técnica del consumidor (Vid. ESTEVARENA, Emilio y BAROCELLI, Sergio S., La protección de los consumidores en plataformas de comercio electrónico, en L.a Ley 2018-C, p. 180).

Frente a esta realidad del comercio electrónico es necesario contar con normas especiales. Es decir, debe existir una adecuado marco normativo para aquellos contratos de consumo en lo que además de carácter internacional se presenta su conclusión de manera electrónica. 
LOS CONTRATOS DE CONSUMO EN EL DERECHO INTERNACIONAL PRIVADO DE FUENTE INTERNA. LA REGULACIÓN DEL CÓDIGO CIVIL Y COMERCIAL DE LA NACIÓN ARGENTINA

Germán E. Gerbaudo 